\section{Lesões buco-dentais em mulheres em situação de violência: um estudo piloto de casos periciados no IML de Belo Horizonte, MG}

\author{
Mouth-dental injuries in women \\ violence victims: A pilot study of \\ registered cases in the Legal Medical \\ Institute of Belo Horizonte, MG
}

\section{Edson José Carpintero Rezende ${ }^{1}$ \\ Tânia Maria Araújo² \\ Maria Antonieta Siqueira Moraes ${ }^{3}$ \\ Judith Sena da Silva Santana² \\ Ronaldo Radicchi ${ }^{4}$}

'Departamento de Odontologia, Centro de Ciências Biológicas e da Saúde, Universidade Estadual de Montes Claros

2Departamento de Saúde - Programa de Pós-graduação Mestrado em Saúde Coletiva, Universidade Estadual de Feira de Santana

${ }^{3}$ Departamento de Odontologia Restauradora, Faculdade de Odontologia, Universidade Federal de Minas Gerais

${ }^{4}$ Associação Brasileira de Odontologia - Seção Minas Gerais

Correspondência: Edson José Carpintero Rezende. Rua Campos Sales, 200 ap.307, Bairro Calafate - Belo Horizonte, MG - CEP: 30480-470. E-mail: edson.carpintero@gmail.com

\section{Resumo}

A violência tem mostrado tendência ascendente, nos últimos anos, no Brasil. Nesse cenário, a violência sofrida pela mulher vem-se tornando mais visível à sociedade a partir das denúncias de agressões sofridas. Este estudo se propõe a descrever dados referentes às lesões corporais na região peribucal em mulheres que sofreram agressão. Foram analisados os registros e laudos encaminhados ao setor de Odontologia do IML de Belo Horizonte, referentes ao período de janeiro de 2001 a junho de 2002. Neste período, foram atendidas 108 mulheres. A faixa etária predominante foi a de 20 a 39 anos $(70,4 \%)$. A maioria dessas mulheres declarou: ser solteira $(63,0 \%)$ e ser natural do interior do Estado $(48,1 \%)$. Quanto à ocupação encontrou-se: $24 \%$ que realizam trabalhos domésticos, $21 \%$ que são donas-de-casa e $14 \%$ que trabalham no comércio. A proporção de mulheres procedentes das Delegacias Seccionais foi maior do que aquelas encaminhadas pelas Delegacias de Mulheres. A lesão de tecido mole mais freqüente foi a laceração; a de tecidos duros e da polpa foram as fraturas de esmalte e dentina sem complicações; a de tecidos periodontais foi a concussão; e foram observadas duas lesões em tecidos ósseos. O estudo permitiu constatar a necessidade de uma coleta de dados mais cuidadosa nos exames periciais, de modo a disponibilizar informação mais detalhada da violência contra as mulheres; além disso, revelou que as lesões buco-dentais são freqüentes e representam uma grande demanda para os serviços odontológicos de saúde pública que prestam esse atendimento.

Palavras-chaves: Violência contra mulher. Violência doméstica. Lesões buco-dentais. 


\section{Abstract}

Violence has been a growing problem in the past years in Brazil. Violence against women has become clearer to society after victims started filing accusations of aggression. This study aims to describe data on lesions in women, victims of aggression in the region of the mouth, sent to the Dental Sector of the Legal Medical Institute in Belo Horizonte, Minas Gerais, Brazil. The records and verdicts of the section from January 2001 to June 2002 were analyzed, when 108 women were seen. Ages ranged mostly between 20 and 39 (70.4\%). Most of them reported being single (63.0\%); $24 \%$ were housemaids; $21.3 \%$ were housewives; $14 \%$ worked in the commerce; and $48.1 \%$ came from the countryside. Victims from the Sectional Police Station were more frequent than those from the Women's Police Station. The most frequent lesion in soft tissues was laceration; in the hard tissues and in the pulp, there were enamel and dentin fractures without complications; concussions prevailed in the periodontal tissues; two lesions in bone tissues were observed. Results pointed out toward the need to take special care in the collection of data during forensic exams in order to better understand the situations related to violence against women; it also showed that the lesions studied are frequent, growing in numbers and represent a major demand for public health dentistry services.

Keywords: Violence against women. Domestic violence. Mouth-dental injuries.

\section{Introdução}

A violência é um problema que se mostra ascendente e vem se tornando foco de discussão na saúde coletiva desde o final da década de $80^{1}$. Essa preocupação se fundamenta num conceito ampliado de saúde, no qual tudo o que representa agravo e ameaça à vida está incluído no universo da saúde pública. A abordagem da violência se expressa com forte ênfase na análise das tendências epidemiológicas e de prevenção à ocorrência de lesões físicas, emocionais e de morte, além de aperfeiçoar e dar qualidade à atenção prestada às vítimas ${ }^{2}$.

A violência, segundo a Organização Mundial de Saúde (2002), pode ser definida como "o uso intencional da força física ou do poder, real ou em ameaça contra si próprio, contra outra pessoa, ou contra um grupo ou uma comunidade, que resulte ou tenha possibilidade de resultar em lesão, morte, dano psicológico, deficiência de desenvolvimento ou privação de liberdade"3.

A violência pode ser dividida em física, psicológica e comportamental. A expressão "violência contra a mulher" associa-se à ocorrência de agressões físicas ou sexuais, porém a grande maioria dos dados disponíveis sugere uma maior ocorrência e/ ou visibilidade das agressões físicas ${ }^{4,5}$. Com o passar dos anos, a violência contra a mulher foi sendo referida de diferentes formas. Durante a primeira metade do século XX, foi retratada como intrafamiliar. Nos anos 70, passou a ser denominada de violência contra a mulher. Na década de 80 , passou a ser chamada de violência doméstica; por fim, a partir da década de 90 , intitula-se violência de gênero. A violência de gênero abrange aquela que é praticada por homens contra mulheres, entre homens e entre mulheres em uma busca por afirmar suas identidades masculinas e femininas ${ }^{6}$. Vale ressaltar que, mesmo na atualidade, ainda se encontra com freqüência as denominações violência contra a mulher e violência doméstica para expressar a violência de gênero, mais especificamente aquela praticada contra 
mulheres. Os perpetradores em geral podem ser os parceiros, os familiares (mãe, pai, irmãos, tios, entre outros), pessoas conhecidas (tais como vizinhos e colegas de escola), estranhos, ou agentes do Esta$\mathrm{do}^{6,7-11}$. A violência contra a mulher ocorre mais freqüentemente no ambiente doméstico, sendo que a maioria das agressões é praticada no interior das residências. Os dados da violência denunciada indicam que é alto o número de mulheres agredidas, ratificando a sua consideração como questão social e como questão de saúde pública $^{2,5}$. Diversos autores apontam que a maioria dos casos de violência reincidirá se não houver alguma ação que interrompa a sua dinâmica ${ }^{6,12,13}$. Em geral, os dados referentes à violência são problemáticos, provisórios e não traduzem a verdade, pois em algumas situações o registro disponível pode ocultar a situação real que expresse o fato ${ }^{1}$. Certamente, esta afirmativa encontrará farto respaldo na violência doméstica contra mulheres, visto que essa realidade só é conhecida parcialmente, mesmo em casos de vítimas fatais ${ }^{14}$. Conhecer os fatores que envolvem essa violência é de suma importância para se apontar soluções para os graves e dispendiosos problemas sociais dela advindos.

Nos últimos anos, as investigações em saúde sobre violência são baseadas em dados de mortalidade devido à disponibilidade das informações sobre óbitos e à dificuldade em se obter dados de morbidade. No Brasil, a produção científica sobre a violência contra a mulher ainda é escassa, e essa violência raramente aparece nas estatísticas de mortalidade, pois na maioria das vezes não resulta em morte. Além disso, as mulheres agredidas dificilmente denunciam em função do medo, da vergonha, ou do vínculo afetivo com o agressor ${ }^{15}$.

As mulheres em situação de violência geralmente são adolescentes e mulheres adultas inseridas num contexto familiar, ou em relações íntimas que não respeitam fronteiras de classe social, cor da pele, religião, idade e escolaridade. Assim, este agravo atravessa todas as classes sociais e não representa privilégio das classes populares, podendo ocorrer uma alta incidência nas camadas sociais superiores ${ }^{16,17}$. O fenômeno da violência de gênero sofrido pelas mulheres desconhece os tipos de cultura e de grau de desenvolvimento econômico, podendo ocorrer em qualquer lugar e podendo ser praticado, em qualquer fase da vida das mulheres, por parte de estranhos ou de parentes e conhecidos ${ }^{13}$.

A violência sofrida pela mulher fere a Constituição Brasileira promulgada em 1988 em seu Art. 5, que reza que “Todos são iguais perante a lei ..."; bem como o seu §I:" - homens e mulheres são iguais em direitos e obrigações, ..." ${ }^{18}$. As lesões sofridas por mulheres podem ser intencionais ou não ${ }^{19}$. A mulher sofre uma violência silenciosa que acontece, principalmente, no interior das famílias e, muitas vezes, não é identificada pelos profissionais de saúde quando há a procura por atendimento em decorrência das lesões sofridas $^{20}$. A região de cabeça e pescoço é um dos sítios mais atingidos nesse tipo de agressão. Dessa forma, observa-se uma alta demanda no atendimento a essas mulheres, ressaltando a fundamental importância do cirurgião dentista nos serviços de saúde que disponibilizam esse profissional para a realização desses procedimentos $^{19,21}$.

Diante dessa realidade, e devido à carência de estudos a respeito da violência de gênero com o enfoque nas lesões bucais e peribucais, e ainda pelo fato de este tipo de violência ser pouco investigado pelos profissionais de saúde ${ }^{4,5}$, este estudo, a partir de registros e laudos procedentes do setor de Odontologia do IML, objetiva descrever os tipos de lesões decorrentes de agressões em mulheres da região metropolitana de Belo Horizonte, avaliando o perfil sociodemográfico das mulheres em situação de violência e caracterizando as lesões ocorridas. Desta forma ressalta-se a participação do cirurgião dentista no atendimento, identificação, prevenção dos agravos à saúde dessas mulheres, oriundos da violência sofrida. 


\section{Métodos}

Esse estudo descritivo sobre a violência de gênero pretende disponibilizar alguns dados relacionados à violência física sofrida por mulheres que foram periciadas no Instituto Médico Legal de Belo Horizonte. Para o presente trabalho, obteve-se uma autorização do Diretor do IML de Belo Horizonte, bem como aprovação pelo Comitê de Ética e Pesquisa do Grupo Santa Casa de Misericórdia de Belo Horizonte. Foi realizado um levantamento de dados em registros e laudos de mulheres vítimas de lesões corporais no complexo estomatognático que foram encaminhadas pelas delegacias e/ou órgãos competentes ao Instituto Médico Legal (IML) de Belo Horizonte, para perícia no Setor de Odontologia Legal. Foram analisados todos os registros de laudos, excetuando-se aqueles referentes a mulheres que sofreram outras lesões corporais específicas, como acidentes com veículos, denúncias de possíveis erros profissionais, exames complementares e de verificação de idade.

O levantamento realizado abrangeu fichas e laudos arquivados durante 18 meses, compreendendo o período de janeiro de 2001 a junho de 2002, preenchidos por funcionários que estiveram neste período desempenhando a função de odontolegista.

Os dados foram compilados para um formulário dividido em duas partes: Parte I (identificatória) e Parte II (descrição da lesão). A Parte I abrangeu informações sobre características das mulheres em situação de violência e da agressão sofrida através dos dados fornecidos pela mesma e coletados nos registros compilados da guia policial de encaminhamento ou do ofício que solicitou o exame, ou ainda do item histórico contido no corpo do laudo. Esses dados incluíram: delegacia de origem da denúncia, idade, profissão, naturalidade, estado civil da vítima, instrumento de agressão, sujeito agressor e seu grau de ligação com a vítima. A parte II foi obtida a partir do exame técnico do Perito, apresentando a quantificação e a descrição das le- sões, permitindo a seguinte classificação: lesões de tecidos moles, de tecidos dentários e da polpa; danos aos tecidos periodontais e aos tecidos ósseos.

As lesões pertinentes aos tecidos moles foram agrupadas segundo a classificação de Peterson et al. ${ }^{22} \mathrm{em}$ : abrasão que envolve as escoriações (desnudamento da epiderme); contusão (equimoses e hematomas) e lacerações (feridas em que há solução de continuidade). No item “outros” foram incluídos os relatos de sintomatologia dolorosa, sem evidência de agressão física.

As lesões pertinentes aos tecidos duros e à polpa foram agrupadas posteriormente em: infração ao esmalte (fissura da coroa dentária); fratura de esmalte; fratura de esmalte e dentina sem complicações (sem exposição pulpar); fratura complicada de coroa (de esmalte e dentina com exposição pulpar); fratura de coroa e raiz sem complicações (esmalte, dentina e cemento sem exposição pulpar); fratura complicada de coroa e raiz (esmalte, dentina e cemento com exposição pulpar) e fratura de raiz ${ }^{23}$.

As lesões pertinentes aos tecidos periodontais foram agrupadas posteriormente em: concussão, subluxação, luxação extrusiva, luxação intrusiva, luxação lateral e avulsão ${ }^{23}$, e outros, quando não enquadradas nas categorias anteriores.

As lesões pertinentes aos tecidos ósseos foram agrupadas posteriormente em: fratura de parede alveolar (tábua óssea alveolar), fratura do processo alveolar em maxila ou mandíbula (de alvéolo), fratura de mandíbula ou de maxila (Le Fort I, II, III) ${ }^{23}$. No item “outros", foram relacionados os relatos de sintomatologia dolorosa, principalmente na região da articulação temporomandibular.

Quanto aos tipos de lesões detectadas, vale ressaltar que há divergência nas definições de alguns termos utilizados nas ciências forenses (Medicina Legal e Odontologia Legal), quando comparados com os utilizados nas áreas clínicas. Dessa forma, foram padronizados nesse trabalho os ter- 
mos adotados por Petersen (1996) e Andreasen \& Andreasen (1994) ${ }^{22,23}$. Assim, é importante ressaltar que o termo laceração não é pertinente à linguagem forense, apesar de ser muito utilizado na área clínica pelos autores acima citados, sendo adotado no presente estudo. Este termo não é utilizado porque em Medicina e Odontologia Legal as lesões produzidas são classificadas de acordo com o instrumento que os produziu. Os instrumentos dilacerantes são definidos como contundentes em sua maioria. Como não existem instrumentos dilacerantes, não há como falar em lesões dilacerantes. Desse modo, a laceração é encarada na linguagem forense como uma solução de continuidade em meio a uma ação contundente ${ }^{24}$.

Após a obtenção do levantamento dos dados, estes foram sistematizados e submetidos a análise descritiva, calculandose freqüências simples, uma vez que se trata de mulheres em situação de violência e das lesões por elas apresentadas.

\section{Resultados}

Em 18 meses investigados neste estudo, um total de 483 laudos em pessoas vivas foram emitidos pelo setor de Odontologia do Instituto Médico Legal de Belo Horizonte, incluindo lesões corporais, exames complementares de lesões corporais, exames de verificação de idade e outros não muito freqüentes, como respostas a quesitos formulados por autoridades para serem respondidos por Peritos Oficiais. Deste total, 164 foram registrados como exames de lesões corporais em mulheres, envolvendo todos os tipos de lesões corporais. Ao todo, 108 mulheres em situação de violência com lesões corporais que foram encaminhadas ao IML por serem vítimas de agressões físicas, constituíram a amostra deste estudo, pois foram excluídos os acidentes de veículos, os erros odontológicos e os laudos registrados como lesões corporais que, na verdade, eram exames complementares.

No primeiro semestre de 2001 foram registradas no setor de Odontologia do IML de Belo Horizonte 55 mulheres que sofreram lesões corporais, enquanto no primeiro semestre de 2002 o número subiu para 67. A média de idade das mulheres estudadas neste estudo foi de 30,3 anos, observando-se que as mulheres em situação de violência se encontravam em uma ampla faixa etária, compreendida entre 12 e 64 anos. A faixa etária predominante observada entre as mulheres examinadas no setor de Odontologia do IML de Belo Horizonte e em situação de violência foi de 20 a 39 anos, representando $70,4 \%$ do total (Tabela 1 ).

As ocupações foram categorizadas e mostram um predomínio de mulheres que trabalhavam com serviços domésticos $(24,1 \%)$ e daquelas que se intitulavam "donas-de-casa” (21,3\%); ou seja, predominaram ocupações relacionadas a atividades do lar, tais como faxineiras, auxiliares de serviço e camareiras, entre outras (Tabela 1).

O local de nascimento das mulheres examinadas revelou que $54,6 \%$ do total eram de migrantes do interior de Minas Gerais ou de outros Estados, sendo 48,1\% oriundas do interior do estado (Tabela 1). Foi observado que $92 \%$ das mulheres que foram encaminhadas por agressão ao IML eram naturais de Minas Gerais.

A maioria das mulheres que sofreu agressões nomeou-se solteira, perfazendo um total de $63 \%$; o percentual de casadas foi menor, apenas 20,4\% (Tabela 1).

Das 108 mulheres estudadas, 63\% foram oriundas de delegacias seccionais (delegacias de plantão noturno e para fins de semana e feriados, não especializadas no atendimento de mulheres em situação de violência) e, destas, 32,3\% representavam violência contra mulheres, pois havia a informação do sujeito agressor. Dos $37 \%$ restantes, 35,2\% foram provenientes da delegacia de mulheres, mesmo quando não se registrou a informação da relação do agressor com a vítima, o que ocorreu em $27,9 \%$ dos laudos. Contudo, como o estatuto da delegacia de mulheres estabelece que toda denúncia ali acolhida represente mulheres que sofreram violência de gêne- 
Tabela 1 - Características sociodemográficas das mulheres vítimas de violência $(n=108)$. Belo Horizonte, 2001-2002.

Table 1 - Sociodemographic characteristics of women victims of violence $(n=108)$. Belo Horizonte, 2001-2002.

\begin{tabular}{|c|c|c|}
\hline Característica & $\mathrm{n}$ & $\%$ \\
\hline \multicolumn{3}{|l|}{ Faixa etária } \\
\hline Até 19 anos & 16 & 14,8 \\
\hline 20 a 29 anos & 38 & 35,2 \\
\hline 30 a 39 anos & 38 & 35,2 \\
\hline 40 a 49anos & 10 & 9,2 \\
\hline 50 a 59 anos & 3 & 2,8 \\
\hline 60 anos ou mais & 3 & 2,8 \\
\hline \multicolumn{3}{|l|}{ Ocupação } \\
\hline Serviços domésticos & 26 & 24,1 \\
\hline Dona-de-casa & 23 & 21,3 \\
\hline Atividades do comércio & 15 & 14,0 \\
\hline Estudante & 11 & 10,2 \\
\hline Cabeleireira + manicure & 4 & 3,7 \\
\hline Professora & 3 & 2,8 \\
\hline Outras ocupações mencionadas / não mencionadas & 25 & 23,0 \\
\hline Não tem ocupação & 1 & 0,9 \\
\hline \multicolumn{3}{|l|}{ Local de Nascimento da vítima } \\
\hline Cidade do interior de Minas Gerais & 52 & 48,1 \\
\hline Belo Horizonte & 48 & 44,4 \\
\hline Outro Estado & 7 & 6,5 \\
\hline Não mencionou & 1 & 0,9 \\
\hline \multicolumn{3}{|l|}{ Situação conjugal } \\
\hline Solteira & 68 & 63,0 \\
\hline Casada & 22 & 20,4 \\
\hline Viúva & 3 & 2,8 \\
\hline União livre & 6 & 5,5 \\
\hline Separada & 9 & 8,3 \\
\hline
\end{tabular}

ro, esses $27,9 \%$, relatados anteriormente, caracterizam essa situação, perfazendo um percentual de $55,5 \%$.

Em 25\% dos casos, o sujeito agressor foi o companheiro; em $3,7 \%$ foram familiares; e em $7,4 \%$ foram conhecidos, perfazendo um total de $36,1 \%$ contra $2,8 \%$ de violência realizada por estranhos, independente da delegacia de origem (Tabela 2). Deve-se registrar o elevado percentual de casos em que o agressor não foi identificado $(61,1 \%)$.

A maioria das lesões corporais estudadas $(49,1 \%)$ foi classificada como agressões nuas, ou seja, aquelas nas quais nenhum instrumento foi utilizado (Tabela 2). Em somente três das lesões restantes foi utili- zado algum tipo de instrumento. Novamente observa-se elevado percentual de informação não relatada $(48,1 \%)$.

As lesões peribucais (em tecidos moles, tecidos duros e na polpa, tecidos periodontais e tecidos ósseos) apresentadas pelas mulheres totalizaram 242 eventos (Tabela 3). Percebe-se, pelos resultados, que uma determinada agressão pode resultar em vários tipos de lesões classificadas em mais de um grupo, ou seja, várias lesões em uma mesma agressão. Uma análise comparativa entre os grupos mostrou que os danos aos tecidos moles foi o grupo que apresentou o maior número de lesões (115 lesões), seguido dos danos aos tecidos periodontais com 71 lesões. 
Tabela 2 - Mulheres vítimas de violência segundo o sujeito agressor e o instrumento utilizado na agressão. Belo Horizonte, 2001-2002.

Table 2 - Aggressors and types of instruments used in aggressions against women victims of violence. Belo Horizonte, 2001-2002.

\begin{tabular}{lcc}
\hline Agressão & $\mathrm{n}$ & $\%$ \\
\hline Sujeito agressor & & \\
$\quad$ Companheiro & 27 & 25,0 \\
Familiares & 4 & 3,7 \\
Conhecidos & 8 & 7,4 \\
Estranhos & 3 & 2,8 \\
Não relatado & 66 & 61,1 \\
Instrumento usado & & \\
Agressões nuas & 53 & 49,1 \\
Instrumentalizadas & 1 & 0,9 \\
Mistas & 2 & 1,9 \\
Não relatado & 52 & 48,1 \\
\hline
\end{tabular}

Tabela 3 - Lesões peribucais em mulheres vítimas de violência segundo o grupo. Belo Horizonte, 2001-2002.

Table 3 - Groups of mouth-dental lesions among women victims of violence. Belo Horizonte, 20012002.

\begin{tabular}{lcc}
\hline Grupo de lesão & $\mathrm{n}$ & $\%$ \\
\hline I (tecidos moles) & 115 & 47,52 \\
III (tecidos periodontais) & 71 & 29,34 \\
II (tecidos duros e da polpa) & 45 & 18,60 \\
IV (tecidos ósseos) & 11 & 4,54 \\
\hline Total & 242 & 100,0 \\
\hline
\end{tabular}

A lesão de Tecidos Moles mais freqüente foi a "laceração", atingindo $49,6 \%$ do total das lesões analisadas, seguida pela contusão e pela abrasão (Tabela 4).

A lesão mais freqüente de tecidos duros e da polpa foi a fratura de esmalte e dentina sem complicações (sem exposição pulpar), perfazendo $37,8 \%$ do total da amostra (Tabela 5).

No grupo das lesões em Tecidos Periodontais, a concussão foi responsável pelo maior percentual $(40,9 \%)$ seguida pela associação da subluxação dentária, luxação extrusiva e luxação lateral, com 33,8\% das lesões (Tabela 6) que possuem prognóstico duvidoso a curto e médio prazo, requerendo uma proservação posterior ao trauma. A avulsão foi responsável por 18,3\% das lesões, tornando as mulheres que so- freram agressão em geral deformadas e com a necessidade do uso de prótese, com a possibilidade de se fazer um implante, ósteo-integrado ou não.

No grupo das lesões em Tecidos Ósseos só foi descrita uma fratura de processo alveolar e uma fratura de mandíbula que totalizaram 18,2\% (Tabela 7). Esse grupo foi o que apresentou menor número de lesões, mas, quando presente, representa uma lesão muito severa, devendo também ser promovido um atendimento imediato.

\section{Discussão}

O aumento progressivo da violência vem se tornando alvo de algumas investigações, pois gera uma demanda para o sistema de saúde no que tange ao atendimen- 
Tabela 4 - Lesões em tecidos moles ente as mulheres vítimas de violência. Belo Horizonte, 2001-2002.

Table 4 - Soft tissue lesions in women victims of violence. Belo Horizonte, 2001-2002

\begin{tabular}{lcc}
\hline Tipos de Lesão & $\mathrm{n}$ & $\%$ \\
\hline Laceração & 57 & 49,56 \\
Contusão & 32 & 27,83 \\
Abrasão & 26 & 22,61 \\
\hline Total & 115 & 100,0 \\
\hline
\end{tabular}

Tabela 5 - Lesões em tecidos duros e da polpa entre as mulheres vítimas de violência. Belo Horizonte, 2001-2002.

Table 5 - Hard tissue and pulp lesions in women victims of violence. Belo Horizonte, 2001-2002

\begin{tabular}{lcc}
\hline Tipos de Lesão & $\mathrm{n}$ & $\%$ \\
\hline Infração do esmalte & 1 & 2,22 \\
Fratura de esmalte & 13 & 28,89 \\
Fratura de esmalte e dentina sem complicações & 17 & 37,78 \\
Fratura complicada da coroa & 12 & 26,67 \\
Fratura de coroa e raiz sem complicações & 1 & 2,22 \\
Fratura complicada de coroa e raiz & 0 & 0,00 \\
Fratura de raiz & 1 & 2,22 \\
\hline Total & 45 & 100,0 \\
\hline
\end{tabular}

Tabela 6 - Lesões em tecidos periodontais das mulheres vítimas de violência segundo o grupo. Belo Horizonte, 2001-2002.

Table 6 - Lesions in periodontal tissues among women victims of violence. Belo Horizonte, 20012002

\begin{tabular}{lcc}
\hline Tipos de Lesão & $\mathrm{n}$ & $\%$ \\
\hline Concussão & 29 & 40,85 \\
Subluxação & 19 & 26,76 \\
Luxação extrusiva & 4 & 5,63 \\
Luxação Instrusiva & 0 & 0,00 \\
Luxação lateral & 1 & 1,41 \\
Avulsão & 13 & 18,31 \\
Outros & 5 & 7,04 \\
\hline Total & 71 & 100,0 \\
\hline
\end{tabular}

Tabela 7 - Lesões em tecidos ósseos das mulheres vítimas de violência. Belo Horizonte, 20012002.

Table 7 - Lesions in bone tissues among women victims of violence. Belo Horizonte, 2001-2002

\begin{tabular}{lcc}
\hline Tipos de Lesão & $\mathrm{n}$ & $\%$ \\
\hline Fratura de parede alveolar & 0 & 0,00 \\
Fratura de processo alveolar em maxila ou mandíbula & 1 & 9,09 \\
Fratura de mandíbula ou de maxila & 1 & 9,09 \\
Outros & 9 & 81,82 \\
\hline Total & 11 & 100,0 \\
\hline
\end{tabular}


to aos que a sofrem, seja logo após a agressão e/ou posteriormente, no acompanhamento das seqüelas produzidas. Fundamenta-se no fato de que as mortes e traumas violentos estão aumentando em larga escala e podem ser prevenidos ${ }^{1}$.

O local de coleta de dados e a qualidade das informações obtidas são fatores que podem fornecer conhecimento mais preciso sobre a situação de violência e tornam-se relevantes para as ações de saúde de base geográfica, uma vez que refletem a especificidade do público alvo da pesquisa. A literatura aponta um estudo em Belo Horizonte com mulheres encaminhadas a instituições de abrigo como medida de prevenções de agressões futuras ${ }^{25}$; dois estudos realizados em dois hospitais públicos no Rio de Janeiro, com atendimento de emergência para mulheres vítimas de violência de gênero ${ }^{21}$; e outro executado em um hospital que oferece atendimento de emergência em Atenas (Grécia) ${ }^{7}$. $O$ fato de a mulher em situação de violência receber atendimento hospitalar pode sugerir uma lesão mais grave, explicitando a necessidade de atendimento médico. Nesse estudo, a presença da lesão foi uma constante, e a gravidade da lesão não foi o fator determinante para a coleta de dados, pois o IML de Belo Horizonte é um órgão pertencente à Polícia Civil de Minas Gerais, que registra e examina todas as vítimas que fazem denúncia e são a ele encaminhadas para exame. Sempre que o crime de lesões corporais é caracterizado, independente da gravidade, as seqüelas decorrentes de agressões físicas são caracterizadas, apontando um forte marcador da violência.

Nessa investigação, a predominância observada na idade das mulheres examinadas no setor de Odontologia do IML de Belo Horizonte, e em situação de violência foi na faixa de 20 a 39 anos, Num estudo desenvolvido na Grécia, a faixa etária encontrada foi de 16 a 62 anos ${ }^{7}$. Em outro estudo realizado também em Belo Horizonte, foi reportado que as mulheres em situação de violência se encontravam na faixa etária entre 16 e $48 \operatorname{anos}^{25}$. Nos dados obtidos em dois hospitais municipais do Rio de Janeiro, observou-se tanto mulheres adolescentes quanto adultas com uma predominância de violência na faixa etária entre 20 a 29 anos $^{21}$.

A qualidade dos dados disponíveis pode representar um dos obstáculos para se conhecer mais a fundo os números reais que expressem a violência sofrida por mulheres. A mulher, inicialmente, é acolhida em uma delegacia ou, dependendo da gravidade das lesões, em uma instituição de saúde. Em cada lugar por onde ela passa há o preenchimento de formulários de identificação e registro, que muitas vezes possuem as mesmas informações, porém nem sempre equivalentes. Além disso, muitas vezes, num momento de grande estresse, durante o acolhimento inicial, pode ocorrer de as pessoas encarregadas de obter e registrar as informações prestadas virem a fazê-lo de maneira intempestiva ou mesmo displicente. Há que ressaltar, ainda, que também, em várias situações, as pessoas não foram devidamente preparadas para exercer tal função.

A ocupação das mulheres, em situação de violência, é uma informação que ilustra a situação descrita acima, pois está contida no item "profissão" da guia policial ou no ofício que solicita a perícia. Esse dado é colhido pelo encarregado do registro do órgão competente que recebeu a denúncia, e não fornece elementos suficientes para se estabelecer se a vítima está naquele momento empregada ou desempregada; se há vínculo empregatício ou não; se exerce atividade remunerada ou não, e se a sua profissão corresponde à ocupação exercida quando da agressão. Assim, não foi possível comparar nossos achados com aqueles de outros estudos analisados que adotaram classificações diversas quanto à categoria profissional, ocupação e profissão. Esta limitação reforça o aspecto de que os dados referentes à violência são problemáticos e provisórios, e não traduzem a verdade, havendo sempre controvérsias ${ }^{1}$. Desse modo, não se pode estabelecer uma 
relação entre a profissão e/ou ocupação exercida pela vítima com as agressões sofridas, assim como foi encontrado em um dos estudos onde se referenciou que a maior parte das mulheres vítimas de violência exercia atividades ligadas ao emprego doméstico ou limpeza ${ }^{26}$.

Uma consideração a mais sobre a qualidade das informações coletadas diz respeito à situação conjugal das mulheres em situação de violência. Deve-se lembrar, aqui, que as informações requeridas na guia não são necessariamente comprovadas, sendo apenas fornecidas verbalmente pela denunciante. Desse modo, não pode ser descartada a possibilidade de que as mulheres que não são legalmente casadas, mas coabitam em uma relação marital com um parceiro fixo, podem se declarar solteiras, representando um fator de interferência no que se considera como número real de mulheres solteiras. A situação inversa, também, é verdadeira, ou seja, a mulher, mesmo não sendo legalmente casada, informa que é casada por estar inserida em uma relação estável.

$\mathrm{O}$ fato de a maioria das mulheres que sofreu violência de gênero ser procedente do interior do Estado de Minas Gerais, ou de outros Estados, pode sugerir que o histórico da sua origem e da migração, e sua inserção em novos contextos socioeconômicos e culturais pode ser um fator de contribuição ou até mesmo de estímulo a um ambiente favorável à ocorrência de violência. Vale ressaltar que este cenário representa apenas uma das expressões de uma condição estrutural totalmente desfavorável, que reforça ainda mais as desigualdades sociais.

As delegacias podem oferecer poderosos indicadores da violência que ocorre na cidade e podem representar uma referência relativa a queixas de caráter mais específico, como as de atendimento às mulheres e idosos. A Delegacia Especializada de Crimes Contra a Mulher (DECCM) de Belo Horizonte, como as outras delegacias similares das demais regiões do país, tem a função de investigar e apurar os delitos contra pessoas do sexo feminino vítimas de violência ${ }^{16}$. As DECCM se estabeleceram, em grande parte, pela dificuldade das mulheres denunciarem violências praticadas contra elas, bem como pela especificidade e pelo substancial aumento que esse tipo de agressão vem apresentando. Quando a mulher em situação de violência denuncia em uma delegacia seccional, além dos registros provenientes das mulheres em situação de violência, são efetuadas todas as outras ocorrências, tais como furtos, assaltos, homicídios etc. que acometem homens, crianças, adultos e idosos.

A relação do sujeito agressor com a mulher agredida foi classificada, nesse estudo, nas seguintes categorias: companheiro, familiar, conhecido e estranho. As agressões por companheiro, familiar ou conhecido são configuradas, por definição, como violência de gênero contra mulheres. Os achados deste estudo revelam a predominância desse tipo de agressão, assim como vários estudos que também relataram que os agressores mais freqüentes eram maridos, companheiros, ex-maridos, amantes, namorados e parentes p,7,9-11. $^{\text {. }}$

A guia emitida pela delegacia e trazida pela denunciante ao IML traz em seu contexto a sua qualificação. Entretanto, a despeito da identificação do sujeito agressor constar no inquérito policial, essa informação não é enviada ao Perito do IML. Nesse estudo, a identificação da relação mulher em situação de violência/agressor ficou comprometida pelo fato de que $61,1 \%$ dos laudos analisados não faziam menção quanto ao sujeito agressor. Esse dado tem sido rotineiramente omitido, sendo descrito por alguns peritos, mas não por outros, no momento do histórico, o que tem dificultado a obtenção de dados mais fidedignos da situação. Muitas vezes, a omissão desta informação relaciona-se ao fato de esta constar no inquérito policial, ou se deve à ausência da pergunta referente ao agressor no momento do atendimento e preenchimento da guia para atendimento pericial no IML. 
O instrumento da agressão utilizado na violência de gênero contra a mulher foi dividido em: agressões nuas, que são efetuadas pelo próprio corpo do agressor; instrumentalizadas e mistas. Este dado esteve ausente em $48,1 \%$ dos casos, pois, na maioria das vezes, esta informação encontrase disponível no boletim de ocorrência ou nos autos do inquérito policial, não estando disponíveis no momento da perícia, a não ser que o perito interrogue a denunciante sobre esta informação. Aqui se repetem, provavelmente, os motivos citados anteriormente sobre a coleta incompleta de dados durante a elaboração do laudo pericial no item histórico, comprometendo os resultados no que se refere a este dado.

Todos os laudos analisados nesse estudo representam perícias executadas em mulheres em situação de violência, que apresentaram lesões na região peribucal, com a prerrogativa de avaliar e descrever as lesões quando estas estavam presentes ou passíveis de descrição. Vários estudos apontam que as regiões da face e da boca estão entre as mais atingidas nas mulheres em situação de violência ${ }^{13,19,21,23}$.

Algumas lesões provavelmente não estiveram evidentes por serem fugazes, pela sua própria natureza, ou porque a periciada demorou a se apresentar para o exame. As lesões corporais por violência recente apresentam maior probabilidade de achados físicos. Entretanto não se pode desprezar ou relacionar o relato de dor com a ausência/presença de agressão, apesar de ser uma informação subjetiva. Nos dados coletados em um hospital de pronto-socorro de Belo Horizonte - Minas Gerais, encontrou-se como lesão mais freqüente dos tecidos moles a laceração, como nesse estudo ${ }^{27}$. A lesão mais freqüente de tecidos duros e da polpa foi a fratura de esmalte e dentina sem complicações, que, associada à fratura de coroa e raiz sem complicações, resultou em $40 \%$ das lesões deste grupo, lesões estas dolorosas pela exposição da dentina e que requerem rápida reconstrução do elemento dentário para restabelecer a função e a estética. A fratura complicada da coroa equivaleu a $26,7 \%$ dos casos.

É digno de nota que alguns tipos de lesões que acometem o sistema estomatognático e a face resultam em danos estéticos abruptos ou sintomatologia dolorosa intensa, requerendo atendimento odontológico imediato, contribuindo com o parecer de Minayo (1994) e Minayo \& Souza (1999) ${ }^{1,2}$ sobre a violência, gerando problema e demanda em saúde pública. Em cada grupo estudado há aquelas lesões consideradas como mais complexas, e portanto necessitando de atendimento dos serviços de saúde que envolvem média e alta complexidade. Dentre essas lesões pode-se citar as lacerações, as fraturas complicadas de coroa e de raiz, as avulsões e todas as fraturas dos ossos.

Não se pode deixar de mencionar os resultados de um estudo realizado na Inglaterra com 100 mulheres espancadas e acolhidas num abrigo. Encontrou-se em 44 delas feridas sangrentas, e em 24 fraturas dentárias ${ }^{9}$. Esses dados podem ser confrontados com o do presente estudo, que encontrou 57 lacerações e 44 fraturas dentárias (incluindo todas as fraturas) nas 108 mulheres examinadas. Sem especificar valores, um estudo mexicano realizado com 57 mulheres mostrou que as lesões mais observadas na violência física foram os hematomas, seguidos das lesões que requerem alguma sutura ${ }^{28}$. Já no estudo realizado na Grécia foram encontrados 21,6\% de hematomas ${ }^{7}$. Neste estudo, as lesões que requerem alguma sutura foram intituladas de lacerações e foram as mais numerosas, seguidas das abrasões e das contusões que incluem os hematomas, mostrando resultados discordantes do estudo citado.

Mesmo quando não puderam ser evidenciadas as lesões, o fato de essas mulheres serem encaminhadas para exame de corpo de delito pressupõe um histórico anterior de agressão física resultante de ato violento. Todas as lesões encontradas no presente estudo foram decorrentes de agressões físicas na região peribucal de 
mulheres vítimas de violência e reafirmam os resultados encontrados em outros estudos que apontam a violência como fator etiológico de traumas que geram lesões na região peribucal, tais como fraturas faciais, lesões em tecidos periodontais e traumas dentários $7,27,29,30$.

Este estudo permitiu constatar a necessidade de uma coleta de dados mais cui- dadosa durante os exames periciais de lesões corporais, de modo a disponibilizar informações mais detalhadas da violência contra as mulheres. Além disso, revelou que as lesões bucodentais são freqüentes, em particular as de tecidos moles, e representam uma grande demanda para os serviços odontológicos de saúde pública que prestam atendimento.

\section{Referências}

1. Minayo MCS. A violência social sob a perspectiva da saúde pública. Cad Saúde Pública 1994; 10(S1): 07-18.

2. Minayo MCS, Souza ER. É possível prevenir a violência? Reflexões a partir do campo da saúde pública. Ciência \& Saúde Coletiva 1999; 4: 7-23.

3. Brasil. Ministério da saúde. Secretaria de Atenção à Saúde. Departamento de ações programáticas estratégicas. Atenção integral para mulheres e adolescentes em situação de violência doméstica $e$ sexual: matriz pedagógica para formação de redes. Brasília; 2006

4. Dantas-Berger SM, Giffin K. A violência nas relações de conjugalidade: invisibilidade e banalização da violência sexual? Cad Saúde Pública 2005; 21: 417-25.

5. Giffin K. Violência de gênero, sexualidade e saúde. Cad Saúde Pública 1994; 10 (S1):146-55.

6. Brasil. Ministério da saúde. Secretaria de vigilância à saúde. Departamento de análise de situação de saúde. Impacto da violência na saúde dos brasileiros. Brasília; 2005.

7. Zacariades N, Koumoura FK, Agouridaki EK. Facial trauma in women resulting from violence by men. J Oral Maxillofac Surg 1990; 48: 1250-3.

8. Adeodato VG, Carvalho RR, Siqueira VR, Souza FGM. Qualidade de vida e depressão em mulheres vítimas de seus parceiros. Rev Saúde Pública 2005; 39: 108-13.

9. Saffioti HIB, Almeida SS. Violência de gênero-Poder e impotência. Rio de Janeiro: Revinter; 1995.

10. Brasil. Ministério da saúde. Atenção a mulheres em situação de violência. Promoção de saúde 2001; 2: 15-7

11. Hedin LW. Physical and sexual abuse against women and children. Curr Opin Obstet Ginecol 2000; 12: 349-355

12. Deslandes SF. O atendimento às vítimas de violência na emergência: "prevenção numa hora dessas?" Ciência \& Saúde Coletiva 1999; 4: 81-94

13. Silva MV. Violência contra a mulher: quem mete a colher? São Paulo: Cortez Editora; 1992.
14. Schraiber LB, D’Oliveira AFPL, França-Júnior I, Pinho AA. Violência contra a mulher: estudo em uma unidade de atenção primária à saúde. Rev Saúde Publica 2002; 36: 470-7.

15. Chesnais JC.. Violência no Brasil. Causas e recomendações políticas para sua prevenção. Ciência \& Saúde Coletiva 1999; 4: 53-69.

16. Aquino EML. Saúde das Mulheres no Brasil: subsídios para o debate sobre o gênero e eqüidade. In: Seminário Eqüidade entre os sexos: uma agenda para a virada do século. São Paulo (Br); 1995. p. 1-36.

17. Goldenberg P, Medrado MA, Paternostro MAN. A violência contra a mulher: uma questão de saúde. In: Medici AC, Labra ME. Mulher, saúde e sociedade no Brasil. Petrópolis: Editora Vozes; 1989. p. 185-200.

18. Duarte GDA Constituição - explicada ao cidadão e ao estudante. Belo Horizonte: Editora Lê; 1990.

19. Gutmann JL, Gutmann MSE. Cause, incidence, and prevention of trauma to teeth. Dent Clin North Am 1995; 39: 1-13.

20. Richardson J, Feder G, Eldrigde S, Chung WS, Coid J, Moorey S. Women who experience domestic violence and women survivors of childhood sexual abuse: a survey of health professionals attitudes and clinical practice. $\mathrm{BrJ}$ Practice 2001; 51, 468-70.

21. Deslandes SF, Gomes R, Silva CMFP. Caracterização dos casos de violência doméstica contra a mulher atendidos em dois hospitais públicos do Rio de Janeiro. Cad Saúde Pública 2000; 16, 129-37.

22. Peterson LJ, Ellis E, Hupp JR, Tucker MR. Cirurgia oral e maxilofacial contemporânea. $2^{\mathrm{a}} \mathrm{ed}$. Rio de Janeiro: Guanabara Koogan; 1996. p. 513-8.

23. Andreasen JO, Andreasen FM. Text book and color atlas of traumatic injuries to the teeth. $3^{\mathrm{a}}$ ed. Copenhagen: Editora Mosby; 1994. p. 150-80.

24. Croce D, Croce-Júnior D. Manual de medicina legal. $4^{\text {a }}$ ed. São Paulo: Editora Saraiva; 1998. p. 182-3. 
25. Alves AM, Coura-Filho P. Avaliação das ações de atenção às mulheres sob violência no espaço familiar, atendidas no Centro de apoio à mulher (Belo Horizonte), entre 1996 e 1998. Ciência \& Saúde Coletiva 2001; 6: 243-57.

26. Meneghel SN, Camargo M, Fasolo LR, Mattiello DA, Silva RCR, Santos TCB et al. Mulheres cuidando de mulheres: um estudo sobre a Casa de Apoio Viva Maria, Porto Alegre, Rio Grande do Sul, Brasil. Cad Saúde Pública 2000; 16: 747-57.

27. Mota CV, Aguiar EG, Dutra, CEA. Levantamento sobre os atendimentos de trauma facial. Rev Gaúcha Odontol 2001; 49: 187-90.
28. Rodriguez JCR, Guerra MCP. Mujeres de Guadalajara y violência doméstica: resultados de um estúdio piloto. Cad Saúde Pública 1996;12: 405-9.

29. Rufino A. Qual será a próxima vítima? Informativo eletrônico IbaseNet. 2003. Disponível em http:// www.ibase.br (Acessado em 27de janeiro de 2003 de http://www.mulhernorap.hpg.ig.com.br / Qual_sera_a_proxima_vitima.htlm \}

30. Garbin CAS, Garbin AJI, Dossi M. Violência doméstica: análise das lesões em mulheres. Cad Saúde Pública 2006, 22: 2567-73.

Recebido em: 31/03/06 Versão final reapresentada em: 23/03/07

Aprovado em: 25/04/07 